\title{
The Integration of Artificial Intelligence in Medical Imaging Practice: Perspectives of African Radiographers
}

\author{
Authors: \\ 1Benard Ohene Botwe, PhD: Sirbenard13@gmail.com /bebotwe@ug.edu.gh: ORCID: 0000-0002-0477- \\ $640 X$ \\ ${ }^{2}$ Theophilus N. Akudjedu, PhD: takudjedu@bournemouth.ac.uk: ORCID: 0000-0003-2423-6897 \\ ${ }^{1}$ William Kwadwo Antwi, PhD: wkantwi@ug.edu.gh: ORCID: 0000-0002-6726-2342 \\ ${ }^{3}$ Prince Rockson, Mphil: Prockson2018@sahs.uhas.edu.gh \\ ${ }^{4}$ Stephen Samson Mkoloma: bishopmkoloma@gmail.com \\ ${ }^{5}$ Elizabeth Olasunkanmi Balogun, MSc: Bethbalo72@gmail.com \\ ${ }^{6}$ Wiam Elshami, PhD: welshami@sharjah.ac.ae \\ 7Joe Bwambale, BSc: Bwajoe25@gmail.com \\ ${ }^{8}$ Caesar Barare, BSc: bsiza1@gmail.com \\ ${ }^{9}$ Sibusiso Mdletshe, PhD: sibusiso.mdletshe@auckland.ac.nz, ORCID: 0000-0002-5418-5122 \\ ${ }^{10}$ Boniface Yao, MSc: Kwame_boniface@yahoo.fr/boniface.yao@infas.edu.ci \\ ${ }^{1}$ Samuel Arkoh, BSc: sampapaarkoh1997@gmail.com

\section{Affiliations:} \\ ${ }^{1}$ Department of Radiography, School of Biomedical and Allied Health Sciences, College of Health Sciences, \\ University of Ghana, Box KB143, Korle Bu, Accra, Ghana. \\ ${ }^{2}$ Institute of Medical Imaging \& Visualisation, Department of Medical Science \& Public Health, Faculty of \\ Health \& Social Sciences, Bournemouth University, Bournemouth, UK. \\ ${ }^{3}$ Department of Medical Imaging, University of Health and Allied Sciences, Ho, Ghana. \\ ${ }^{4}$ Ocean Road Cancer Institute, Tanzania. \\ ${ }^{5}$ National Orthopaedic Hospital, Igbobi, Lagos, Nigeria. \\ ${ }^{6}$ Department of Medical Diagnostic Imaging, College of Health Sciences, University of Sharjah, United \\ Arab Emirates \\ ${ }^{7}$ Society of Radiography of Uganda, Uganda. \\ ${ }^{8}$ Kenyatta National Hospital, Kenya. \\ ${ }^{9}$ University of Auckland, Faculty of Medical and Health Sciences, Department of Anatomy and Medical \\ Imaging, Auckland, New Zealand. \\ ${ }^{10}$ National Institute for health technologists' training (INFAS) Côte d'Ivoire, Department of medical imaging \\ and radiotherapy
}

Corresponding author: ${ }^{1}$ Benard Ohene Botwe: Sirbenard13@gmail.com /bebotwe@ug.edu.gh ${ }^{1}$ Department of Radiography, School of Biomedical and Allied Health Sciences, College of Health Sciences, University of Ghana, Box KB143, Korle Bu, Accra, Ghana. Tel: +233244029365

Keywords: Artificial Intelligence; Medical Imaging; Radiography; Africa; Online Surveys 


\begin{abstract}
Introduction: The current technological developments in medical imaging are centred largely on the increasing integration of artificial intelligence (AI) into all equipment modalities. This survey assessed the perspectives of African radiographers on the integration of $\mathrm{Al}$ in medical imaging in order to offer unique recommendations to support the training of the radiography workforce.

Methods: An exploratory cross-sectional online survey of radiographers working within Africa was conducted from March to August 2020. The survey obtained data about their demographics and perspectives on Al implementation and usage. Data obtained were analysed using both descriptive and inferential statistics.

Results: A total of 1020 valid responses were obtained. Majority of the respondents ( $n=883,86.6 \%)$ were working in general X-ray departments. Of the respondents, $84.9 \%(n=866)$ indicated that Al technology would improve radiography practice and quality assurance for efficient diagnosis and improved clinical care. Fear of job losses following the implementation of Al was a key concern of most radiographers $(n=625,61.3 \%)$.

Conclusion: Generally, radiographers were delighted about the integration of Al into medical imaging, however; there were concerns about job security and lack of knowledge. There is an urgent need for stakeholders in medical imaging infrastructure development and practices in Africa to start empowering radiographers through training programmes, funding, motivational support, and create clear roadmaps to guide the adoption and integration of Al in medical imaging in Africa.

Implication for practice
\end{abstract}

The current study offers unique suggestions and recommendations to support the training of the African radiography workforce and others in similar resource-limited settings to provide quality care using Alintegrated imaging modalities. 


\title{
The Integration of Artificial Intelligence in Medical Imaging Practice: Perspectives of African Radiographers
}

\begin{abstract}
Introduction: The current technological developments in medical imaging are centred largely on the increasing integration of artificial intelligence (AI) into all equipment modalities. This survey assessed the perspectives of African radiographers on the integration of $\mathrm{Al}$ in medical imaging in order to offer unique recommendations to support the training of the radiography workforce.

Methods: An exploratory cross-sectional online survey of radiographers working within Africa was conducted from March to August 2020. The survey obtained data about their demographics and perspectives on Al implementation and usage. Data obtained were analysed using both descriptive and inferential statistics.

Results: A total of 1020 valid responses were obtained. Majority of the respondents ( $n=883,86.6 \%)$ were working in general X-ray departments. Of the respondents, $84.9 \%(n=866)$ indicated that Al technology would improve radiography practice and quality assurance for efficient diagnosis and improved clinical care. Fear of job losses following the implementation of Al was a key concern of most radiographers $(n=625,61.3 \%)$.

Conclusion: Generally, radiographers were delighted about the integration of Al into medical imaging, however; there were concerns about job security and lack of knowledge. There is an urgent need for stakeholders in medical imaging infrastructure development and practices in Africa to start empowering radiographers through training programmes, funding, motivational support, and create clear roadmaps to guide the adoption and integration of $\mathrm{Al}$ in medical imaging in Africa.

Implication for practice

The current study offers unique suggestions and recommendations to support the training of the African radiography workforce and others in similar resource-limited settings to provide quality care using Alintegrated imaging modalities.
\end{abstract}

Keywords: Artificial Intelligence; Medical Imaging; Radiography; Africa; Online Surveys 


\section{Introduction}

Artificial intelligence (Al) broadly refers to the theory and development of computer systems capable of performing tasks normally requiring human intelligence, such as visual perception, speech recognition, decision-making, and language translation. ${ }^{1,2}$ These advanced computer-controlled systems have the capacity to accomplish tasks commonly associated with human intelligence. ${ }^{2}$ Machine and deep learning algorithms are subsets of Al and their applications in medical imaging practice is gradually becoming more common. ${ }^{3-7} \mathrm{Al}$ is recognised to offer unique advantages in medical imaging practice such as reduced rates of diagnostic errors, workplace-related stress and provide clinical decision support to radiologists and radiographers. ${ }^{6-8}$ The joint statement from the International Society of Radiographers and Radiological Technologists (ISRRT) and the European Federation of Radiographer Societies (EFRS) ${ }^{9}$, argued that Al systems could optimise imaging workflows and potentially aid dose reduction, increase research efficiency and consistently deliver high quality planning processes. It is therefore generally accepted that Al has come to stay as an integral tool for practice and medical imaging professionals have been vanguards of this movement. ${ }^{10-12}$

Although radiographers have acknowledged these technologies within the profession, ${ }^{3}$ there are concerns about Al. Some radiographers have indicated that the emergence of Al and its application could have a negative impact on their core skills. ${ }^{3}$ Issues of ethics and potential medico-legal concerns in relation to image manipulation and cyber security were also highlighted. ${ }^{13}$ In the African context, the lack of adequate workforce training and the technical expertise, data-right frameworks, public policies, cost of Al equipment installation/management, fear of consequent job losses and internet connectivity challenges have been previously reported. ${ }^{14}$ Nevertheless, there is an increasing advocacy for the integration of $\mathrm{Al}$ in the core aspects of imaging especially in low-resource settings. ${ }^{4,12,15}$

For efficient use of $\mathrm{Al}$, radiographers would need to adapt their practices to ensure that the new technology is utilised in line with accredited standards for maximum patient benefit. ${ }^{9}$ With the emergence of baseline guidance statements ${ }^{9,10}$ for future radiography practice and the inescapable market progression resulting from the continuous application of cutting-edge medical imaging technologies ${ }^{16-18}$, there is a demand for radiographers with requisite expertise and knowledge of Al. This warrants the understanding of the current perspectives of radiographers in Africa on the integration of Al into medical imaging practice. This study aimed to comprehensively assess the perspectives of radiographers in Africa about $\mathrm{Al}$ in order to provide unique recommendations to support the training of this workforce in readiness to provide quality patient care using this technology. 


\section{Methods}

An exploratory cross-sectional survey of radiographers working within Africa was conducted. The catchment of radiographers eligible and included were diagnostic radiographers working across the five regions of Africa ${ }^{20}$ during the study period. A previously validated research instrument ${ }^{19}$ was adapted for the current study. A representative group of the research team reviewed the adopted questionnaire and recommended areas for modification. These recommendations comprise the inclusion of variables such as country of residence and knowledge on previous computer coding/programming experience. Briefly, the adapted instrument broadly includes questions relating to demographics, general attitudes and perspectives on job security, the future of medical Imaging including workforce development and ethics in relation to the integration of $\mathrm{Al}$ (Appendix 1). The content validity of the final instrument was assessed and approved by three faculty members in radiography with experience ranging between 5 to 15 years.

The survey was piloted in three African countries (Ghana, Nigeria and Tanzania) to address reliability concerns and to ensure there were no ambiguities. In order to gain an unbiased and representative insight from across Africa, the research instrument was translated into French and Arabic by academic radiographers in the research team with proficiency in both English and either of the two languages. A test-retest analysis was used to approve the reliability of the French and Arabic versions of the research instrument.

The survey was hosted online using Google Forms (Google, Mountain View, CA). The link to the survey was shared amongst the leadership of the professional radiography societies across Africa via email and was advertised on social media platforms (WhatsApp, Twitter, Facebook, Linkedln etc). Time frame for the survey response was five months (March 25th to August 31st, 2020) with weekly reminders on respective social media to maximise response. The Ethics and Protocols Review Committee of the School of Biomedical and Allied Health Sciences of the University of Ghana approved the study prior to its commencement (SBAHS/AA/RAD/29245/2019-2020) and all the respondents provided electronic informed consent for participation. To ensure confidentiality, participants' responses were kept anonymous and stored on a computer with an encrypted password.

\section{Statistical Analysis}

Data from the survey were downloaded from Google Forms, analysed using the Statistical Package for the Social Sciences (SPSS) version 23 (IBM Corp, NY, USA). The response to rating questions/items were assigned scores (1-5) on the Likert scale, corresponding to responses (strongly agree $=5$, agree=4, neutral=3, disagree=2, strongly disagree $=1$ ). Spearman's rank-order correlation was used to investigate the relationship between some of the demographic variables and respondents' perspectives on the 
integration of Al in medical imaging. A two-tailed $\alpha$ level of 0.05 was used for testing statistical significance in all analyses. For easy presentation of the results, the "strongly agreed" and "agreed" responses were grouped together as an "agreement response" while the "strongly disagree" and "disagree" responses were also grouped together as a "disagreement response".

\section{Results}

A total of 1020 valid responses [English: $(n=950)$, Arabic: $(n=40)$ and French $(n=30)$ ] were obtained, comprising of $69.6 \%$ male $(n=710)$ and female $(n=310,30.4 \%)$ respondents. Demographic details of the respondents are presented in Table 1. Responses were received from 51.8\% ( $n=28 / 54)$ of countries across Africa (Figure 1). Peak responses were received from Nigeria ( $n=254,24.9 \%)$, Ghana $(n=157,15.3 \%)$ ] and Tanzania ( $n=190,18.6 \%)$ ] (Figure 1). Eight hundred and sixty-six (84.9\%) of the respondents indicated that Al technology would improve general radiography practice and quality assurance for efficient diagnosis and improved clinical care of patients (Table 2). Details of the respondents' general attitudes about the emerging integration and use of Al in medical imaging in Africa are presented in Table 2.

Of the respondents, $61.3 \%(n=625)$ indicated that Al tools could replace the job of most radiographers and negatively affect the radiography profession in Africa rather than being an assistive tool in easing workload (Table 3). Further details of the respondents' perspectives on job security with the emerging integration and use of Al in medical imaging in Africa is presented in Table 3. The respondents' perspectives on the future of $\mathrm{Al}$ in medical imaging in Africa are presented in Table 4.

The score for respondents' general attitudinal perspectives showed significant positive correlations with age $\left(r_{s}=0.83, p=0.008\right)$ and years of practice $\left(r_{s}=0.108, p=0.001\right)$. However, no significant positive correlation was noted with education levels $\left(r_{s}=0.60, p=0.345\right)$. Respondents' score for perspective on job security significantly correlated positively with age $\left(r_{s}=0.136, p=0.001\right)$, years of practice $\left(r_{s}=0.154, p=0.01\right)$ and educational levels $\left(r_{s}=0.209, p=0.001\right)$.

\section{Discussion}

Radiographers are experiencing a massive technological change in their field that will significantly impact the profession. ${ }^{12,21,22}$ To facilitate the successful adoption of Al in medical imaging practice, considering the overriding positive implications of Al implementation, this survey sought to broadly evaluate the perspective of African radiographers on the integration of $\mathrm{Al}$ in medical imaging. To the best 
of our knowledge this is the first study that have assessed the perspective of radiographers in Africa about the integration of $\mathrm{Al}$ in medical imaging practice.

A total of 1020 responses were obtained with 710 male respondents, highlighting male dominance of the sample. Currently, no data exist on the total number of radiographers to suggest male dominance of the radiography workforce in Africa. However, the general observed trend in some previous studies ${ }^{23,24}$ indicates a male dominance radiography workforce in some African countries, contrary to the finding of female dominance reported in the United Kingdom and mainland Europe. ${ }^{25}$ Responses were received from all the five geographical regions of Africa ${ }^{20}$, specifically, from 28 out of the 54 countries of the continent. Irrespective of respondent's expertise (Figure 1B), they held the view that Al would advance general radiography practice, particularly, in the context of image quality improvement for diagnostic precision to enhance patient care (Table 2). This perspective was supported by their indication of awareness of Al trends in medical imaging (78.3) and excitement about the global use of Al in medical imaging (80.2\%). The position share by these respondents could be because of their knowledge that Al systems have the capacity to accomplish tasks commonly associated with human intelligence. $^{2}$

The majority of respondents (76.0\%) had a positive opinion about Al as an assistive technology in optimising radiation dose levels. It was very re-assuring that the majority $(80.2 \%)$ felt that Al would ensure the production of quality images with greater benefits than harm to patients as reported previously. ${ }^{26,27}$ These perspectives are very encouraging as the concepts mentioned are very important in radiographic practice. ${ }^{9}$ Similar evidence suggests that Ghanaian radiographers thought of Al as the future of medical imaging ${ }^{10}$.

Prespane et $\mathrm{al}^{28}$ reported several potential clinical applications of $\mathrm{Al}$ in diagnostic imaging such as image acquisition, image processing and reporting, data storage among others. The majority (86.1\%) of respondents in the current study, believe that, Al tools that support image reporting (through the flagging) of common conditions like tuberculosis would be very important, particularly in Africa. This is because infectious diseases like tuberculosis are common in Africa, as such, Al would augment the relatively small radiology workforce and the expertise required for diagnostic image reporting and interpretation in Africa. Evidence suggest that radiographers approved of the implementation of $\mathrm{Al}$ technologies because of several other advantages beyond image acquisition. ${ }^{3}$

Al technology would require some knowledge in coding and programming for effective implementation in practice. It was therefore encouraging that more than half (61.9\%) of the respondents, had basic knowledge of coding or programming (see Table 1). Notwithstanding, some respondents' views 
were found to reflect negatively on job security regardless of their age and educational level. Particularly, $67.3 \%$ of respondents thought that Al could replace radiographers and adversely affect their profession. Similarly, a previous study ${ }^{28}$ reported some doubts among radiologists about their looming job security moving forward with the emerging trends in Al technologies. Although, there exist general anxiety that Al may substitute human employment ${ }^{29}$, there is no evidence to suggest that this would be the case. ${ }^{4}$ This finding may be due to lack of knowledge in line with a recent report. ${ }^{30}$ Interdepartmental communication and clear guidelines can facilitate the understanding of the role of Al in medical imaging. Consistently, technological changes and development have unswervingly, impacted on the radiography profession with the practice developing and acclimating in response to the operation of new technologies and cutting-edge imaging prospects presented by their implementation. ${ }^{3,11}$ Therefore, the assertion on job insecurity and salary reduction is difficult to accept as Al has not demonstrated how it could for example, replace the human face of patient positioning by radiographers for various imaging investigations and the necessary instructions that they have to provide patients referred to the imaging department.

Radiographers, however, should be assured that $\mathrm{Al}$ is a potential support to the practice of their profession. ${ }^{3}$ Respondents believed that Al would eventually change radiographers' role leading to extended practices. However, previous studies ${ }^{8-11}$, suggest that it would advance the practice and create other opportunities but will not change the core roles of radiographers entirely. There is a global interest in radiography role extension due to increased radiology investigations and career development. ${ }^{11,31,32}$ It is therefore recommended that radiographers prepare themselves through education (e.g., CPD activities, post graduate studies, seminars etc.) for the job opportunities that Al would present to medical imaging professionals.

Legal implications as a result of Al integration in medical imaging is anticipated. Currently, no clear laws or policy frameworks are available to guide the use of Al in medical imaging and healthcare in general. ${ }^{33}$ It was therefore not surprising that the majority (45.5\%) of respondents in the current study felt that the future applications of Al in Africa might encompass errors in clinical radiography practice and unethical utilisation of patient data. This suggests the critical need for governance policies in relation to $\mathrm{Al}$ before its full implementation in Africa.

Respondents' general attitudinal perspective scores strongly correlated positively with age and years of practice but not with the level of education. This trend is explained by the lack of core Al components in the current curriculum of radiography education in Africa and most other training 
institutions globally. ${ }^{30}$ Notably, there are efforts for curriculum revisions to address this in the near future. . $^{3,4,9,11}$

The findings of this study are potentially reflective of other low-resource settings, considering the similar healthcare resource challenges within these communities. However, the survey did not fully address this particular subject; therefore, future studies may be needed using in-depth qualitative approaches to explore the impact of work settings on the perceptions of Al amongst radiographers. Moreover, the study is likely limited by the use of an online exploratory approach for data collection, thus, the sampling used for this research is not proportionate, resulting in countries with large populations and large number of radiographers having small responses, and vice versa.

\section{Conclusion}

The findings indicate that radiographers working in Africa have positive perspectives about the integration of $\mathrm{Al}$ in medical imaging. However, concerns about job security regarding the integration of $\mathrm{Al}$ in medical imaging were eminent. Just like other transformative and revolutionary technologies, there are potential challenges that would be integral to the implementation of Al in medical imaging in Africa. Lack of knowledge, funds, regulatory policies and support systems were identified as key barriers to the effective implementation of Al which should be given attention by stakeholders. The current study offers unique suggestions and recommendations in order to support the training of the African radiography workforce and others in similar resource-limited settings to provide quality care using Al-integrated imaging modalities.

\section{Conflicts of Interest}

None

\section{Funding}

None 


\section{References}

1. Ranschaert E.R., Duerinckx A.J, Algra P, Kotter E, Kortman H, Morozov S. Advantages, Challenges, and Risks of Artificial Intelligence for Radiologists. In: E.R. Ranschaert, S. Morozov and P.R. Algra (eds). Artificial Intelligence in Medical Imaging: Opportunities, Applications and Risks, Cham: Springer. 2019 p.329-346

2. Frankenfield, J. (2019, November 18). How Artificial Intelligence Works. Retrieved January 19, 2020, from https://www.investopedia.com/terms/a/artificial-intelligence-ai.asp

3. Hardy $\mathrm{M}$, Harvey $\mathrm{H}$. Artificial intelligence in diagnostic imaging: impact on the radiography profession. Br J Radiol 2019; 92:20190840. https://doi.org/10.1259/ bjr.20190840.

4. Murphy A, Liszewski B. Artificial intelligence and the medical radiation profession: how our advocacy must inform future practice. J Med Imag Radiat Sci 2019;50(4S2):S15e9. https://doi.org/10.1016/j.jmir.2019.09.001.

5. Litjens G, Kooi T, Bejnordi BE, et al. A survey on deep learning in medical image analysis. Med Image Anal. 2017;42:60-88. doi: 10.1016/j.media.2017.07.005.

6. Kitson, S. (2020, March 8). Artificial Intelligence - medical imaging innovation. Retrieved from https://openmedscience.com/artificial-intelligence-medical-imaging/

7. Gore JC. Artificial intelligence in medical imaging. Magnetic Resonance Imaging 68(2020), A1-A4

8. Lakhani P, Prater AB, Hutson RK, Andriole KP, Dreyer KJ, Morey J, et al. Machine learning in radiology: applications beyond image interpretation. J Am Coll Radiol 2018; 15: 350-9. doi: https://doi.org/10.1016/j.jacr.2017.09.044

9. International Society of Radiographers and Radiological Technologists, The European Federation of Radiographer Societies. Artificial Intelligence and the Radiographer/Radiological Technologist Profession: A joint statement of the International Society of Radiographers and Radiological Technologists and the European Federation of Radiographer Societies. Radiography (Lond). 2020;26(2):93-95. doi:10.1016/j.radi.2020.03.007

10. Chaix, B., Bibault, J. E., \& Pienkowski, A., et al. (2019). When Chatbots meet patients: one-year prospective study of conversations between patients with breast cancer and a Chatbot. JMIR Cancer 5, e12856.

11. Lewis SJ, Gandomkar Z, Brennan PC. Artificial Intelligence in medical imaging practice: looking to the future. J Med Radiat Sci. 2019, 66(4):292-295. doi: 10.1002/jmrs.369.

12. American Society of Radiologic Technologists. The artificial intelligence era: the role of radiologic technologists and radiation therapists. Albuquerque: ASRT Foundation; 2020.

13. Iannucci JM, Howerton LJ. Dental radiography: principles and techniques, 5th Ed. St. Louis, MO. Elsevier. 2017.

14. Nyathi T, Chirwa T, van der Merwe D. A survey of digital radiography practice in four South African teaching hospitals: an illuminative study. Biomed Imaging Interv J. 2010;6(1):e5. doi:10.2349/biij.6.1.e5

15. Wagner JB. Artificial Intelligence in Medical Imaging. Radiol Technol. 2019;90(5):489-501.

16. Mollura DJ, Culp MP, Pollack E, Battino G, Scheel JR, Mango VL, Elahi A, Schweitzer A, Dako F. Artificial Intelligence in Low- and Middle-Income Countries: Innovating Global Health Radiology. Radiology. 2020,201434. doi: 10.1148/radiol.2020201434. 
17. IAEA Brief (2016). Human health: enhancing patient care in Africa through safe medical imaging. Retrieved from: https://www.iaea.org/sites/default/files/16/11/enhancing-patiient-care-inafrica-through-safe-medical-imaging.pdf

18. East Coast Polytechnic Institute. (2020). How medical imaging advances have changed the world. https://www.ecpi.edu/blog/medical-imaging-advances-have-changed-world. Accessed $27 / 07 / 2020$

19. Botwe OB, Antwi KW, Arko S. Akudjedu T. Radiographers' perspectives on the emerging integration of artificial intelligence into medical imaging: The Ghana study. Journal medical radiation sciences. DOI: 10.1002/jmrs.460.

20. The United Nations Statistics Division. Standard country or area codes for statistical use (M49). Retrieved from: https://unstats.un.org/unsd/methodology/m49/. 20/08/2020.

21. Morozov S, Ranschaert E.R, Algra PR. Introduction: Game Changers in Radiology. In: E.R. Ranschaert, S. Morozov and P.R Algra (eds). Artificial Intelligence in Medical Imaging: Opportunities, Applications and Risks, Cham: Springer. 2019.p3-5

22. Kulkarni S, Seneviratne N, Baig MS, and Khan AHA, "Artificial Intelligence in Medicine: Where Are We Now?," Academic Radiology, vol. 27, no. 1. Elsevier USA, pp. 62-70, Jan. 01, 2020, doi: 10.1016/j.acra.2019.10.001.

23. Anim-Sampong S, Arthur L, Nkansah JA, Botwe BO. Women in Radiography Practice in Ghana: Motivating and Demotivating Factors. Radiol Technol. 2018;89(4):337-343.

24. Luntsi G, Muhammed R, Nwobi IC, Njiti M, Nkubli FB. Radiography Profession Regulation, Practice and Challenges in Northern Nigeria. J Assoc Rad Niger, 2015; 29 (1): 1 - 8

25. Akudjedu TN, Lawal O, Sharma M, Elliott J, Stewart S, Gilleece T, McFadden S, Franklin JM. Impact of the COVID-19 pandemic on radiography practice: findings from a UK radiography workforce survey. BJR Open. 2020 Sep 2;2(1):20200023. doi: 10.1259/bjro.20200023.

26. Wang $Y, Y u B$, Wang $L$, et al. 3D conditional generative adversarial networks for high-quality PET imageestimation at low dose. Neurolmage 2018; 174: 550-62.

27. Wolterink J, Leiner T, Viergever T, Isgum I. Generativeadversarial networks for noise reduction in low dose CT. IEEE Trans Med Imaging 2017; 36: 2536-45.10.

28. Pesapane F, Codari M, Sardanelli F. Artificial intelligence in medical imaging: threat or opportunity? Radiologists again at the forefront of innovation in medicine. Eur Radiol Exp. 2018 Oct 24;2(1):35. doi: 10.1186/s41747-018-0061-6.

29. Felten, Edward W. and Raj, Manav and Seamans, Robert, The Occupational Impact of Artificial Intelligence: Labor, Skills, and Polarization (September 8, 2019). NYU Stern School of Business, Retrieved from: http://dx.doi.org/10.2139/ssrn.3368605

30. Abuzaid MM, Elshami W, Tekin H, Issa B. Assessment of the Willingness of Radiologists and Radiographers to Accept the Integration of Artificial Intelligence Into Radiology Practice. Acad Radiol. 2020 Oct 29:S1076-6332(20)30553-5. doi: 10.1016/j.acra.2020.09.014.

31. Abuzaid MM, Elshami W, McConnell J, Baird M. Changing the model of radiography practice in the UAE: A snapshot of a profession in transition. Radiography. 2020 Jun 26.

32. Wuni AR, Courtier N, Kelly D. Developing a policy framework to support role extension in diagnostic radiography in Ghana. J Med Imaging Radiat Sci. 2020 Oct 17:S1939-8654(20)303088. doi: 10.1016/j.jmir.2020.09.013. 
33. Mahomed S. Healthcare, artificial intelligence and the Fourth Industrial Revolution: ethical, social and legal considerations. South Afr J Bioeth Law. (2018) 11:93-5. doi:

10.7196/SAJBL.2018.v11i2.00664

\section{Figure Legend}

Figure 1: Geographical distribution of respondents across Africa (A) and Professional categories and specialties of respondents (B), Africa map showing distribution of respondents (C). Note: CA: Central Africa, EA: East Africa: NA: North Africa: SA: Southern Africa, WA: West Africa. In B, respondents selected more than one option, so the sum of the percentages are more than $100 \%$.

\section{Table Legend}

Table 1: Demographic distribution of respondents.

Table 2: Attitudinal perspectives on the emerging integration and use of $\mathrm{Al}$ in medical imaging in Africa

Table 3: Perspectives on job security with the emerging integration and use of $\mathrm{Al}$ in medical imaging in Africa

Table 4: Perspectives on the future of the emerging integration and use of Al in medical imaging in Africa 


\section{Acknowledgments}

We would like to appreciate all the radiographers who took time to participate in this study. We are also grateful to Mr. Michael Amankwah for assisting in translating the French survey data into English. 
Table 1: Demographic distribution of respondents.

\begin{tabular}{|c|c|}
\hline Demographic & $n(\%)$ \\
\hline \multicolumn{2}{|c|}{ Gender } \\
\hline Male & $710(69.6)$ \\
\hline Female & $310(30.4)$ \\
\hline \multicolumn{2}{|c|}{ Age range (years) } \\
\hline$\leq 20-29$ & $386(37.8)$ \\
\hline $30-39$ & $388(38.0)$ \\
\hline $40-49$ & $167(16.4)$ \\
\hline $50-59$ & $60(5.9)$ \\
\hline 60 and above & 19 (1.9) \\
\hline \multicolumn{2}{|c|}{ Workplace setting } \\
\hline Private & $364(35.7)$ \\
\hline Public & $581(57.0)$ \\
\hline Quasi-government & $64(6.3)$ \\
\hline Others & $11(1.1)$ \\
\hline \multicolumn{2}{|c|}{ Years of practice (years) } \\
\hline$\leq 5$ & $463(45.4)$ \\
\hline $6-10$ & $238(23.3)$ \\
\hline $11-15$ & $131(12.8)$ \\
\hline $16-20$ & $91(8.9)$ \\
\hline 21 and above & $97(9.5)$ \\
\hline \multicolumn{2}{|c|}{ Highest educational level } \\
\hline Certificate & $12(1.2)$ \\
\hline Diploma & $301(29.5)$ \\
\hline $\mathrm{BSc} / \mathrm{BTech}$ & $482(47.3)$ \\
\hline Masters & $186(18.2)$ \\
\hline PGCert/DP & $7(0.7)$ \\
\hline $\mathrm{PhD}$ & $27(2.6)$ \\
\hline Others & $5(0.5)$ \\
\hline \multicolumn{2}{|c|}{ Knowledge on coding/programming } \\
\hline Competent & 64 (6.3) \\
\hline Basic concepts & 631 (61.9) \\
\hline Not at all & 325 (31.9) \\
\hline
\end{tabular}




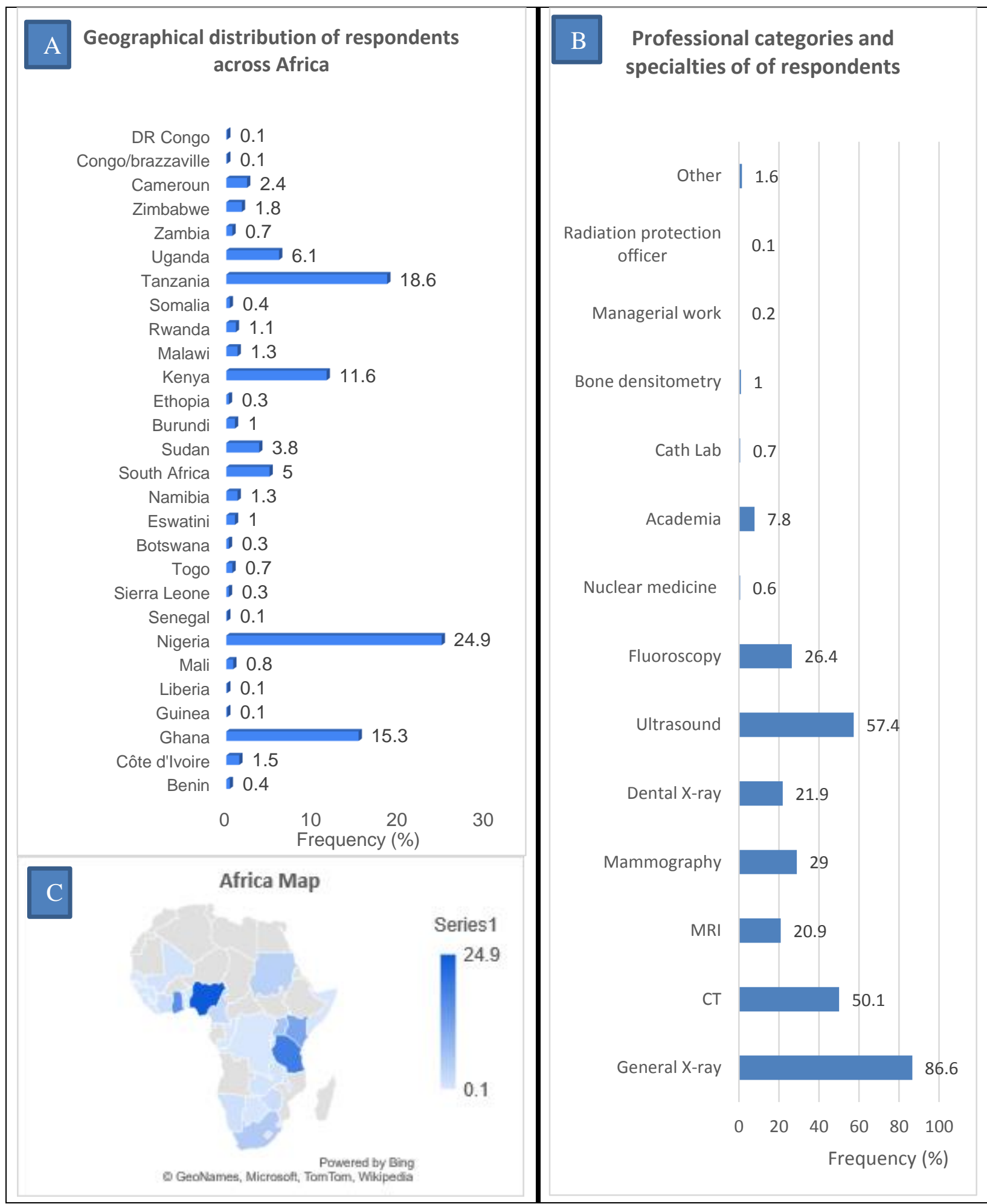

Figure 1: Geographical distribution of respondents across Africa (A) and professional categories and specialties of respondents (B), Africa map showing distribution of respondents (C). In $B$, respondents selected more than one option, so the sum of the percentages are more than $100 \%$. 
Table 2: Attitudinal perspectives on the emerging integration and use of Al in medical imaging in Africa

\begin{tabular}{|c|c|c|c|}
\hline \multirow[t]{2}{*}{ Statements } & \multicolumn{3}{|c|}{ Responses $n(\%)$} \\
\hline & Agreement & Neutral & Disagreement \\
\hline $\begin{array}{l}\text { I am aware of } \mathrm{Al} \text { as an emerging } \\
\text { trend in medical imaging in Africa. }\end{array}$ & 799(78.3) & 202(19.8) & 19(1.9) \\
\hline $\begin{array}{l}\text { I believe most of my patients would } \\
\text { be excited about the use of } \mathrm{Al} \\
\text { technologies in their standard care. }\end{array}$ & 704(69.0) & $271(26.5)$ & $45(4.4)$ \\
\hline $\begin{array}{l}\text { Al could help reduce radiation dose } \\
\text { levels whiles maintaining optimal } \\
\text { image quality in medical imaging. }\end{array}$ & $834(82.8)$ & 159(15.6) & $27(2.6)$ \\
\hline $\begin{array}{l}\text { Al technology would improve general } \\
\text { radiography practice and quality } \\
\text { assurance for its efficient diagnosis } \\
\text { and improved clinical care of my } \\
\text { patients. }\end{array}$ & $866(84.9)$ & $124(12.2)$ & $30(2.9)$ \\
\hline $\begin{array}{l}\text { The introduction of Al technologies } \\
\text { in medical imaging could provide an } \\
\text { avenue for more research to improve } \\
\text { practice and patient care. }\end{array}$ & $924(90.6)$ & $78(7.6)$ & $18(1.8)$ \\
\hline $\begin{array}{l}\text { I am excited about the integration of } \\
\text { Al tools into medical imaging } \\
\text { practice worldwide. }\end{array}$ & $836(82.0 \%)$ & $146(14.3)$ & $38(3.7)$ \\
\hline $\begin{array}{l}\text { I am very concerned about the } \\
\text { integration of } \mathrm{Al} \text { into medical } \\
\text { imaging practice worldwide. }\end{array}$ & 689(67.5) & $226(22.2)$ & 105(10.3) \\
\hline $\begin{array}{l}\text { The integration of Al into medical } \\
\text { imaging practice in Africa would } \\
\text { introduce more benefits than harm. }\end{array}$ & 775(76.0) & $205(20.1)$ & 40(3.9) \\
\hline
\end{tabular}


Table 3: Perspectives on job security with the emerging integration and use of $\mathrm{Al}$ in medical imaging in Africa

\begin{tabular}{|c|c|c|c|}
\hline \multirow[t]{2}{*}{ Statements } & \multicolumn{3}{|c|}{ Responses $n(\%)$} \\
\hline & Agreement & Neutral & Disagreement \\
\hline $\begin{array}{l}\text { Al tools could replace most } \\
\text { radiographers' jobs and negatively } \\
\text { affect the radiography profession in } \\
\text { Africa rather than being an assistive } \\
\text { tool in easing my workload. }\end{array}$ & 625(61.3) & 154(15.1) & $241(23.6)$ \\
\hline $\begin{array}{l}\text { Al tools could replace the job of } \\
\text { most radiologists/reporting } \\
\text { radiographers and negatively affect } \\
\text { the radiology profession in Africa } \\
\text { especially in the role of image } \\
\text { interpretation. }\end{array}$ & 686(67.3) & 149(14.6) & $185(18.1)$ \\
\hline $\begin{array}{l}\text { I have a concern that the role of Al } \\
\text { as an assistive tool can potentially } \\
\text { cause a reduction in my basic salary } \\
\text { and eventually displace me from my } \\
\text { job in the future. }\end{array}$ & 590(57.8) & 176(17.3) & $254(24.9)$ \\
\hline $\begin{array}{l}\text { Al would change the role of } \\
\text { radiographers leading on to } \\
\text { extended practices. }\end{array}$ & 779(76.4) & 136(13.3) & $105(10.3)$ \\
\hline
\end{tabular}


Table 4: Perspectives on the future of the emerging integration and use of $\mathrm{Al}$ in medical imaging in Africa

\begin{tabular}{|c|c|c|c|c|}
\hline \multirow{2}{*}{\multicolumn{2}{|c|}{ Statements }} & \multicolumn{3}{|c|}{ Responses $n(\%)$} \\
\hline & & Agreement & Neutral & Disagreement \\
\hline \multicolumn{2}{|c|}{$\begin{array}{l}\text { I require further education and/or training to } \\
\text { be able to embrace these emerging Al trends } \\
\text { in medical imaging? }\end{array}$} & $943(92.5)$ & $48(4.7)$ & $29(2.8)$ \\
\hline \multicolumn{2}{|c|}{$\begin{array}{l}\text { It is important for radiography departments in } \\
\text { Africa to start planning for Al and machine } \\
\text { learning tools? }\end{array}$} & $900(88.2)$ & $97(9.5)$ & $23(2.3)$ \\
\hline \multicolumn{2}{|c|}{$\begin{array}{l}\text { The use of Al tools could lead to unethical } \\
\text { utilisation of patient data for unwarranted } \\
\text { commercial purposes. }\end{array}$} & $463(45.4)$ & $352(34.5)$ & $205(20.1)$ \\
\hline \multicolumn{2}{|c|}{$\begin{array}{l}\text { There is a possibility of errors associated with } \\
\text { Al technologies integrated into my clinical } \\
\text { radiography practice. }\end{array}$} & $653(64.0)$ & $263(25.8)$ & $104(10.2)$ \\
\hline Questions & & Options & & Response $n(\%)$ \\
\hline \multirow{7}{*}{$\begin{array}{l}\text { What do you see } \\
\text { as the single } \\
\text { greatest barrier to } \\
\text { yourself or others } \\
\text { in learning } \\
\text { about Al? }\end{array}$} & \multicolumn{3}{|c|}{ Lack of dedicated courses and learning materials } & $219(21.5)$ \\
\hline & \multicolumn{3}{|c|}{ Lack of mentorship, guidance and support from "experts" } & 136(13.3) \\
\hline & \multicolumn{3}{|c|}{$\begin{array}{l}\text { Lack of evidence-based material and proof of improved clinical } \\
\text { outcomes }\end{array}$} & $117(11.5)$ \\
\hline & \multicolumn{3}{|c|}{ Lack of time to learn new technologies } & $33(3.2)$ \\
\hline & \multicolumn{3}{|c|}{ Lack of funding/ investment for new technologies } & $360(35.3)$ \\
\hline & \multicolumn{3}{|c|}{ Lack of motivation for change and interest to learn } & $66(6.5)$ \\
\hline & \multicolumn{3}{|l|}{ Fear of the unknown } & $89(8.7)$ \\
\hline \multirow{4}{*}{$\begin{array}{l}\text { What sort of Al } \\
\text { tools would you } \\
\text { prioritise for } \\
\text { medical imaging } \\
\text { practice in Africa? }\end{array}$} & \multicolumn{3}{|c|}{$\begin{array}{l}\text { Tools that support image reporting by detecting or flagging } \\
\text { common conditions like tuberculosis. }\end{array}$} & $879(86.1)$ \\
\hline & \multicolumn{3}{|c|}{ Tools that improve scanning efficiency } & $126(2.4)$ \\
\hline & \multicolumn{3}{|c|}{$\begin{array}{l}\text { Tools that help identify poor patient positioning prior to } \\
\text { imaging studies }\end{array}$} & $10(1)$ \\
\hline & \multicolumn{3}{|c|}{$\begin{array}{l}\text { Tools that improve the efficiency of workflow for booking scans } \\
\text { and radiology appointments }\end{array}$} & $5(0.5)$ \\
\hline
\end{tabular}




\section{Appendix 1 \\ QUESTIONNAIRE}

The Integration of Artificial Intelligence in Medical Imaging Practice: Perspectives of African Radiographers

\section{Section A: Participant Demographics}

We will not collect any information that is will lead to personal identification, however it would be very helpful to know your country of residence, where you work and general demographics.

1. What is your gender?
a. Male
b. Female
c. Prefer not to say we should consider trans gender....

2. What is your age?
a. 20 - 29 years old
b. 30 - 39 years old
c. $40-49$ years old
d. 50 - 59 years old
e. 60 years or above

3. Where do you work (which country)?

4. Which setting best describes your workplace?
a. Community clinic setting
b. Rural/ District setting
c. Urban setting
d. University/ Academic setting
e. Other

5. Which best describes the organisational set-up or structure of your facility?
a. Government Facility
b. Quasi-government Facility
c. Military Facility
d. Private Facility
e. Other

6. How long have you been working as a radiographer?
a. $<5$ years
b. 6-10 years
c. $11-15$ years
d. $16-20$ years
e. 21 - 25 years
f. $>26$ years

7. What is your highest level of education (academic qualification attained)?
a. Certificate
b. Diploma
c. Bachelor's degree
d. Master's degree 

e. PhD
f. Others

8. Which medical imaging modality (s) do you use for your daily work or are you competent at using for your assigned roles? (Please select those that apply)
a. General X-ray
b. Computed Tomography
c. Magnetic Resonance Imaging
d. Fluoroscopy
e. Mammography
f. Ultrasound
g. Dental X-ray
h. Others

9. Do you consider yourself to have any previous computer coding/ programming experience?
a. None at all
b. I am familiar with basic commands and concepts
c. I am able to perform some computer coding/programming
d. I am competent at computer coding/programming
e. I am very experienced in computer coding/programming

\section{Section B: General Attitudes and Perspectives}

Please let us know about any general attitudes you have about the emerging integration and use of Al in medical imaging in Africa.

10. I am aware of Al as an emerging trend in medical imaging in Africa.
a. Strongly Agree
b. Agree
c. Not Sure
d. Disagree
e. Strongly Disagree

11. I believe most of my patients would be excited about the use of Al technologies in their standard care.
a. Strongly Agree
b. Agree
c. Not Sure
d. Disagree
e. Strongly Disagree

12. Al could help reduce radiation dose levels whiles maintaining optimal image quality in medical imaging.
a. Strongly Agree
b. Agree
c. Not Sure
d. Disagree
e. Strongly Disagree

13. Al technology would improve general radiography practice and quality assurance for its efficient diagnosis and improved clinical care of my patients.
a. Strongly Agree
b. Agree 

c. Not Sure
d. Disagree
e. Strongly Disagree

14. The introduction of Al technologies in medical imaging could provide an avenue for more research to improve practice and patient care.
a. Strongly Agree
b. Agree
c. Not Sure
d. Disagree
e. Strongly Disagree

15. I am excited about the integration of AI tools into medical imaging practice worldwide.
a. Strongly Agree
b. Agree
c. Not Sure
d. Disagree
e. Strongly Disagree

16. I am very concerned about the integration of Al into medical imaging practice worldwide.
a. Strongly Agree
b. Agree
c. Not Sure
d. Disagree
e. Strongly Disagree

18. The integration of Al into medical imaging practice in Africa would introduce more benefits than harm.
a. Strongly Agree
b. Agree
c. Not Sure
d. Disagree
e. Strongly Disagree

\section{Section C: Perspectives on Job Security}

Please let us know about your perspective on job security with the emerging integration and use of Al in medical imaging in Africa.

17. Al tools could replace most radiographers' jobs and negatively affect the radiography profession in Africa rather than being an assistive tool in easing my workload.
a. Strongly Agree
b. Agree
c. Not Sure
d. Disagree
e. Strongly Disagree

18. Al tools could replace the job of most radiologists/reporting radiographers and negatively affect the radiology profession in Africa especially in the role of image interpretation.
a. Strongly Agree
b. Agree
c. Not Sure
d. Disagree
e. Strongly Disagree 
19. I have a concern that the role of $\mathrm{Al}$ as an assistive tool can potentially cause a reduction in my basic salary and eventually displace me from $\mathrm{my}$ job in the future.
a. Strongly Agree
b. Agree
c. Not Sure
d. Disagree
e. Strongly Disagree

20. Al would change the role of radiographers leading on to extended practices.
a. Strongly Agree
b. Agree
c. Not Sure
d. Disagree
e. Strongly Disagree

\section{Section D: The Future of Al in medical Imaging: Workforce development \& Ethics}

Please let us know about your perspective on the future of the emerging integration and use of $\mathrm{Al}$ in medical imaging in Africa.

21. Would you require further education and/or training to be able to embrace this emerging Al trends in medical imaging?
a. Strongly Agree
b. Agree
c. Not Sure
d. Disagree
e. Strongly Disagree

22. What do you see as the single greatest barrier to yourself or others in learning about AI? (Select those that apply)
a. Lack of dedicated courses and learning materials
b. Lack of mentorship, guidance and support from "experts"
c. Lack of evidence based material and proof of improved clinical outcomes
d. Lack of time to learn new technologies
e. Lack of funding/ investment for new technologies
f. Lack of motivation for change and interest to learn
g. Fear of the unknown

23. It is important for radiography departments in Africa to start planning for Al and machine learning tools?
a. Strongly Agree
b. Agree
c. Not Sure
d. Disagree
e. Strongly Disagree

24. The use of Al tools could lead to unethical utilisation of patient data for unwarranted commercial purposes.
a. Strongly Agree
b. Agree
c. Not Sure
d. Disagree
e. Strongly Disagree 
25. There is a possibility of errors associated with Al technologies integrated into my clinical radiography practice.
a. Strongly Agree
b. Agree
c. Not Sure
d. Disagree
e. Strongly Disagree

26. What sort of Al tools would you prioritise for medical imaging practice in Africa? (Please pick top three options)
a. Tools that support image reporting by detecting or flagging common conditions like tuberculosis.
b. Tools that help to prioritise abnormal studies for reporting
c. Tools that improve scanning efficiency (e.g. reduce time for MRI sequences/ radiation dose on $\mathrm{CT} /$ conventional $\mathrm{x}$-ray etc)
d. Tools that help identify poor patient positioning prior to imaging studies
e. Tools that identify life threatening injuries/pathologies for triage purposes
f. Tools that improve the efficiency of workflow for booking scans and radiology appointments 